\title{
Dramatic interannual changes of perennial Arctic sea ice linked to abnormal summer storm activity
}

\author{
James A. Screen, ${ }^{1}$ Ian Simmonds, ${ }^{1}$ and Kevin Keay ${ }^{1}$ \\ Received 24 February 2011; revised 4 April 2011; accepted 4 May 2011; published 4 August 2011.
}

[1] The perennial (September) Arctic sea ice cover exhibits large interannual variability, with changes of over a million square kilometers from one year to the next. Here we explore the role of changes in Arctic cyclone activity, and related factors, in driving these pronounced year-to-year changes in perennial sea ice cover. Strong relationships are revealed between the September sea ice changes and the number of cyclones in the preceding late spring and early summer. In particular, fewer cyclones over the central Arctic Ocean during the months of May, June, and July appear to favor a low sea ice area at the end of the melt season. Years with large losses of sea ice are characterized by abnormal cyclone distributions and tracks: they lack the normal maximum in cyclone activity over the central Arctic Ocean, and cyclones that track from Eurasia into the central Arctic are largely absent. Fewer storms are associated with above-average mean sea level pressure, strengthened anticyclonic winds, an intensification of the transpolar drift stream, and reduced cloud cover, all of which favor ice melt. It is also shown that a strengthening of the central Arctic cyclone maximum helps preserve the ice cover, although the association is weaker than that between low cyclone activity and reduced sea ice. The results suggest that changes in cyclone occurrence during late spring and early summer have preconditioning effects on the sea ice cover and exert a strong influence on the amount of sea ice that survives the melt season.

Citation: Screen, J. A., I. Simmonds, and K. Keay (2011), Dramatic interannual changes of perennial Arctic sea ice linked to abnormal summer storm activity, J. Geophys. Res., 116, D15105, doi:10.1029/2011JD015847.

\section{Introduction}

[2] Arctic sea ice cover has declined rapidly over the last three decades [Serreze et al., 2007; Stroeve et al., 2007; Comiso et al., 2008; Simmonds and Keay, 2009; Screen and Simmonds, 2010a], with the largest loss observed in the month of September [Simmonds and Keay, 2009]. Feedbacks associated with the dwindling ice cover have strongly enhanced recent Arctic climate change [Screen and Simmonds, 2010a, 2010b]. Climate models project that the September ice cover will disappear altogether during this century [Stroeve et al., 2007; Boé et al., 2009] and possibly even within the next few decades [Wang and Overland, 2009].

[3] The sea ice decline has accelerated in the last decade and in September 2007 the sea ice reached a record low, around $40 \%$ below average [Comiso et al., 2008; Simmonds and Keay, 2009]. A host of studies have considered the decline in perennial sea ice and, in particular, the causes of the extraordinary September 2007 sea ice minimum. The emerging picture is that a wide range of processes are acting in concert, including changes in cloud cover [Francis and Hunter, 2007; Kay et al., 2008; Schweiger et al., 2008], wind [Wang et al., 2009; Ogi et al., 2010], atmospheric heat

\footnotetext{
${ }^{1}$ School of Earth Sciences, University of Melbourne, Melbourne, Victoria, Australia.

Copyright 2011 by the American Geophysical Union. 0148-0227/11/2011JD015847
}

transport [Graversen et al., 2010] and oceanic heat transport [Woodgate et al., 2010]. Furthermore, the ice loss has likely been amplified by strong positive feedbacks, including the ice-albedo feedback [Perovich et al., 2008; Serreze et al., 2009; Screen and Simmonds, 2010a, 2010b], and the ice pack has been becoming increasingly vulnerable due to progressive thinning [Maslanik et al., 2007; Lindsay et al., 2009]. However, the relative importance of myriad processes and how they are interconnected remains uncertain.

[4] Many of the mechanisms that have been invoked to help explain year-to-year sea ice variability are, in fact, intimately associated with changes in cyclone activity. For instance, the September sea ice extent appears sensitive to changes in seasonal mean sea level pressure (MSLP) [Ogi and Wallace, 2007; Deser and Teng, 2008; Wang et al., 2009], wind [Ogi et al., 2010] and cloud [Kay et al., 2008; Eastman and Warren, 2010], all of which are closely connected with cyclones. However, given the inherent nonlinearity in the surface wind stress and heat fluxes, their accurate evaluation requires a knowledge of atmospheric conditions on all time scales, and changes in monthly or seasonal-mean variables may not be sufficient to explain how sea ice interacts with the atmosphere [Tsukernik et al., 2010]. A fuller perspective is provided by considering changes in the synoptic weather systems (e.g., cyclones) themselves. Here we examine the role of cyclone activity in recent sea ice variability, which has, somewhat surprising, received relatively little attention to date. 
[5] Previous studies have examined Arctic cyclone variability on a range of time scales from seasonal to multidecadal. It has been noted that Arctic cyclone activity has a seasonal maximum in summer [Zhang et al., 2004; Serreze and Barrett, 2008; Simmonds et al., 2008]. On interannual time scales, cyclone activity is closely related to the largescale modes of atmospheric variability, namely the Arctic Oscillation and North Atlantic Oscillation [Zhang et al., 2004; Serreze and Barrett, 2008; Simmonds et al., 2008]. Since the late 1940s, some authors have suggested significant increases in Arctic cyclone activity [Zhang et al., 2004; Sorteberg and Walsh, 2008; Sepp and Jaagus, 2011], coupled with decreases in midlatitude cyclone activity and consistent with a poleward shift of the storm tracks [McCabe et al., 2001; Zhang et al., 2004]. Simmonds et al. [2008] also found an increase in summer cyclone frequency over the period 1958-2006. In contrast, using the same data set but a different cyclone tracking algorithm, Serreze and Barrett [2008] found no significant change in summer cyclone frequency over the period 1958-2005. Furthermore, considering only data since 1979, Simmonds et al. [2008] found no significant trends in cyclone occurrence or in their characteristics. The focus of all these studies was Arctic cyclone variability rather than sea ice variability. That said, Zhang et al. [2004] identified that variations in cyclone activity corresponded reasonably well with alternations between cyclonic and anticyclonic regimes of the Arctic Ocean and sea ice motion. However, these authors do not provide a quantitative analysis of this association nor do they examine how the regime changes effect sea ice extent. The relationships between sea ice cover and cyclones have been considered to some extent by, for example, Sorteberg and Kvingedal [2006] and Lukovich and Barber [2006]. The former study found covariability between winter Barents Sea ice extent and regional cyclone activity, and the latter showed sensitivity of the Beaufort Sea ice gyre to changes in local storminess. At even smaller scales, single storms have been shown to exert strong influence on the underlying ice and Fram Strait ice outflow [Brümmer et al., 2003, 2008]. Here our focus is on the larger-scale relationships between Arctic-wide sea ice area and cyclones rather than regional interactions.

[6] The results presented build on the study of Simmonds and Keay [2009]. That study examined the relationships between September sea ice extent and September cyclone characteristics. It identified statistically significant associations between sea ice and both cyclone strength and size, but not the number of cyclones. Here we expand on Simmonds and Keay [2009] by considering not only instantaneous associations but also lead and lag relationships. In doing so, we reveal new insights that were not previously apparent. Foremost, it is shown that changes in the cyclone occurrence during late spring and early summer have preconditioning effects on the sea ice cover and therefore exert a strong influence on the amount of sea ice remaining at the end of the melt season.

\section{Data Sets}

[7] The analysis primarily draws upon cyclone statistics derived from the University of Melbourne cyclone finding and tracking algorithm [Murray and Simmonds, 1995;
Simmonds et al., 2008; Simmonds and Keay, 2009]. The algorithm objectively identifies cyclones at 6-hourly intervals based on the structure of the MSLP fields and identifies both open and closed low pressure systems. Herein we refer to the number of identified lows as the cyclone count. By joining the cyclone locations at each time step, the scheme calculates the path of each cyclone. This path is referred to as the cyclone track and the number of tracks as the track count. Note the difference between the cyclone count and the track count. For example, over a $24 \mathrm{~h}$ period, a persistent cyclone would give a cyclone count of 4 ( 1 count per 6-hourly time step) but a track count of 1 (all points are associated with the same system). Thus, the track count conveys the number of distinct cyclones whereas the cyclone count also includes information on the longevity of the systems. The cyclone tracking scheme has been shown to perform well in a number of comparisons [Pinto et al., 2005; Raible et al., 2008]. The input data for the tracking scheme were 6-hourly global MSLP reanalyses from the JRA-25 data set [Onogi et al., 2007] over the 31 year period 1979-2009.

[8] Before deciding on the use of JRA-25, we performed a number of comparisons with alternate reanalyses to gain some insight into the sensitivity of the cyclone statistics to the choice of reanalysis. We compared the Arctic-mean (latitudes $>70^{\circ} \mathrm{N}$ ) cyclone counts derived from JRA-25 and three other commonly used reanalyses (ERA-Interim, ERA-40 and NCEP-NCAR; see Screen and Simmonds [2011a, and references therein] for details of these). Small climatological differences were identified between the reanalyses that appeared to partly relate to horizontal resolution (in general the higher resolution reanalyses depicted more cyclones). However, all four reanalyses exhibited very similar interannual variability. It is this variability - rather than the mean state - that is of primary interest to the present study. The cyclone counts were highly correlated between the reanalyses during their overlapping periods (e.g., $r=0.87-0.95$ for May-June-July; MJJ). Such agreement is reassuring as it suggests that the cyclone statistics are not strongly influenced by the reanalyses' unconstrained internal variability, and that they are insensitive to the choice of reanalysis. Therefore, we show results only from one reanalysis. Our final choice of JRA-25 arose because of two ancillary factors. First, JRA-25 covers the entire modern satellite era (1979 onwards) whereas ERA-Interim and ERA-40 do not (ERA-Interim starts in 1989 and ERA-40 ends in 2002). Second, JRA-25 is newer, higher resolution and more sophisticated than the NCEP-NCAR reanalysis. Although these advances do not appear to strongly affect the variability of Arctic cyclones, they may have resulted in improvements in other aspects. An additional advantage of choosing JRA-25 is consistency with the earlier work of Simmonds and Keay [2009].

[9] In addition to the cyclone tracking data we use the following: September-mean sea ice concentrations from the UK Hadley Centre ice and sea surface temperature data set [Rayner et al., 2003], monthly and 6-hourly mean MSLP from JRA-25, monthly mean surface wind stress fields from JRA-25, monthly mean sea ice motion vectors from the Polar Pathfinder satellite product [Fowler, 2003], and monthly mean total cloud cover from International Satellite Cloud Climatology Project D2 data set [Rossow and Schiffer, 1999]. 


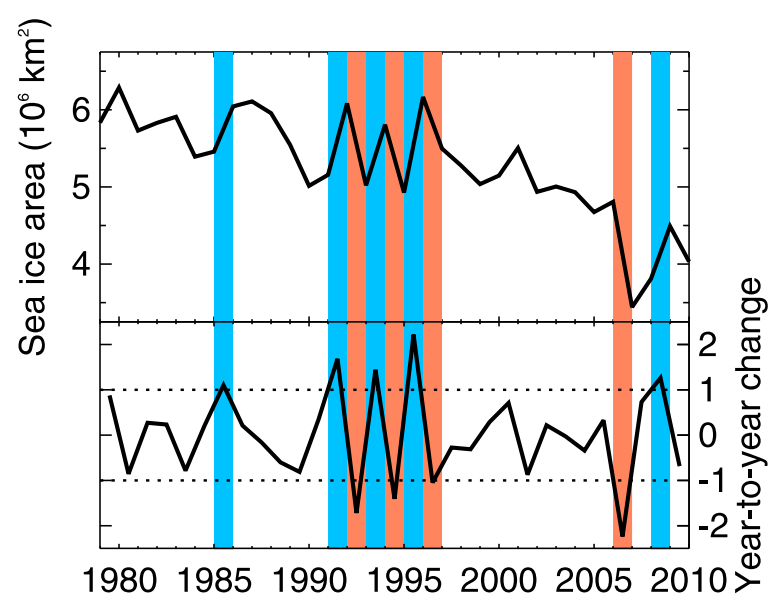

Figure 1. Time series of (top) September sea ice area $\left(10^{6} \mathrm{~km}^{2}\right)$ and (bottom) its year-to-year changes (in units of $1 \sigma)$. The colored bands highlight year-to-year gains (blue) and losses (red) of sea ice area that are greater or less than $1 \sigma$ from the 30 year mean.

[10] We define the Arctic as the region north of $70^{\circ} \mathrm{N}$, the high Arctic as latitudes $80-90^{\circ} \mathrm{N}$, the low Arctic as latitudes $70-80^{\circ} \mathrm{N}$ and the midlatitudes as $40-70^{\circ} \mathrm{N}$. The sea ice area is calculated from area-weighted sea ice concentrations over the entire northern ice-covered region.

\section{Results}

\subsection{Rapid Sea Ice Change}

[11] Figure 1 shows the September sea ice area (SIA) over the period 1979-2010. September is the month of annual lowest ice cover and the September SIA is of especial interest because it reflects the area of perennial ice: ice that has survived at least one full melt season and will thicken during the cold season, thereby increasing its chances of survival through the following melt season. The September SIA exhibits a well-documented downward linear trend [Serreze et al., 2007; Stroeve et al., 2007; Simmonds and Keay, 2009]. Superimposed on this decline is substantial interannual variability. Large shifts in the September SIA of over a million square kilometers have occurred from one year to the next. In what follows, we focus on these rapid ice change events. Calculating the year-to-year changes in SIA $\left(\triangle\right.$ SIA $=$ SIA $^{\mathrm{y}}-$ SIA $^{\mathrm{y}-1}$, where $\mathrm{y}$ is the year $)$ reveals that the largest single-year loss of September SIA occurred between 2006 and 2007. September 2007 has the lowest sea ice area in the modern satellite record. However, 2006-2007 is not unique in displaying a large single-year change in September SIA. The gain of SIA between 1995 and 1996 is of comparable magnitude to the loss of SIA between 2006 and 2007. In addition to 2007, three other years display a loss of SIA from the previous year of greater than one standard deviation $(\sigma): 1993,1995,1997$. Five years display gains of SIA from the previous year of greater than $1 \sigma$ : 1986, 1992, 1994, 1996 and 2009. The same years are identified if the $\triangle$ SIA and its $\sigma$ are calculated from linearly detrended SIA rather than the raw data.

[12] Here we explore the role of changes in cyclone activity, and related factors, in driving these pronounced year-to-year changes in September SIA, primarily using composite means. The four years with a $\Delta$ SIA of greater than $1 \sigma$ (shown by red shading in Figure 1) form the "ice loss years" (ILYs) composite. The five years with a $\Delta$ SIA of less than $-1 \sigma$ (blue shading in Figure 1) form the "ice gain years" (IGYs) composite. Such an approach has the advantage of revealing any nonlinearities in the relationships (for example, the SIA may be more sensitive to an increase in cyclones than a decrease in cyclones, or vice versa) that are unaccounted for when using (linear) correlations or regressions.

\subsection{Cyclones}

[13] Figure 2 shows the Arctic-mean cyclone count anomalies occurring in each month between March and November during the IGYs (blue line) and ILYs (red line), and their difference (ILYs minus IGYs; black line). Consistent with Simmonds and Keay [2009], we find no clear association between changes in September SIA and the number of Arctic cyclones occurring in September. During both ILYs and IGYs the number of Arctic cyclones occurring in September is near average. However, expanding on earlier work, stronger relationships are found between the September SIA changes and the number of cyclones in the preceding months of May, June and July. The ILYs are associated with anomalously low cyclone occurrence during late spring and early summer. Considering the months separately, July is the only month with a composite-mean anomaly of greater than $1 \sigma$ magnitude. The MJJ-mean cyclone count anomaly during ILYs is -42.4 , which can be compared to the $1 \sigma$ value of 33.5. This implies that reductions in MJJ storm frequency precede the major single-year losses in perennial sea ice cover. In contrast, the IGYs are associated with anomalously high cyclone occurrence during late spring and summer. However, these anomalies are smaller than those for the ILYs (the MJJ-mean cyclone count anomaly during IGYs is 20.3). Although it is not the primary focus of this study, we note that there is no clear difference in the cyclone count between IGYs and ILYs during the months immediately following September, implying that changes in September SIA do not strongly

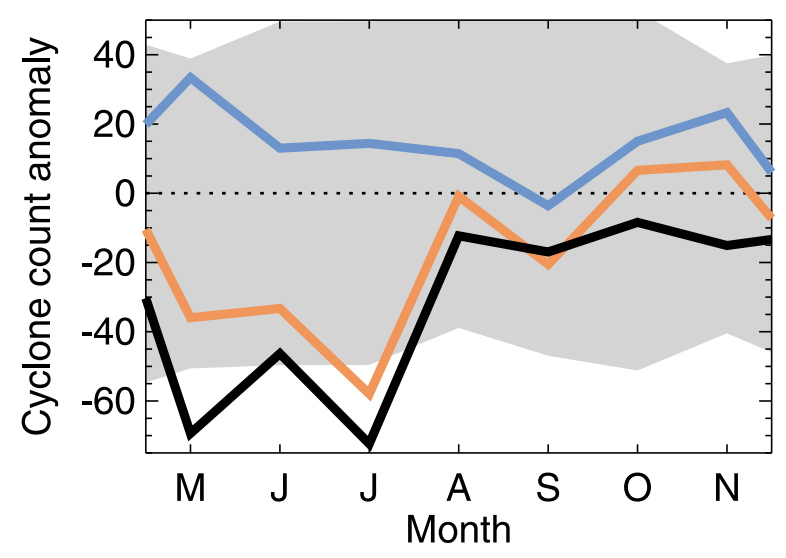

Figure 2. Composite-mean monthly mean Arctic cyclone count anomalies during March to November of the ILYs (red) and IGYs (blue) and their difference (black). The gray shading denotes values that are within $\pm 1 \sigma$ of the 30 year mean. 


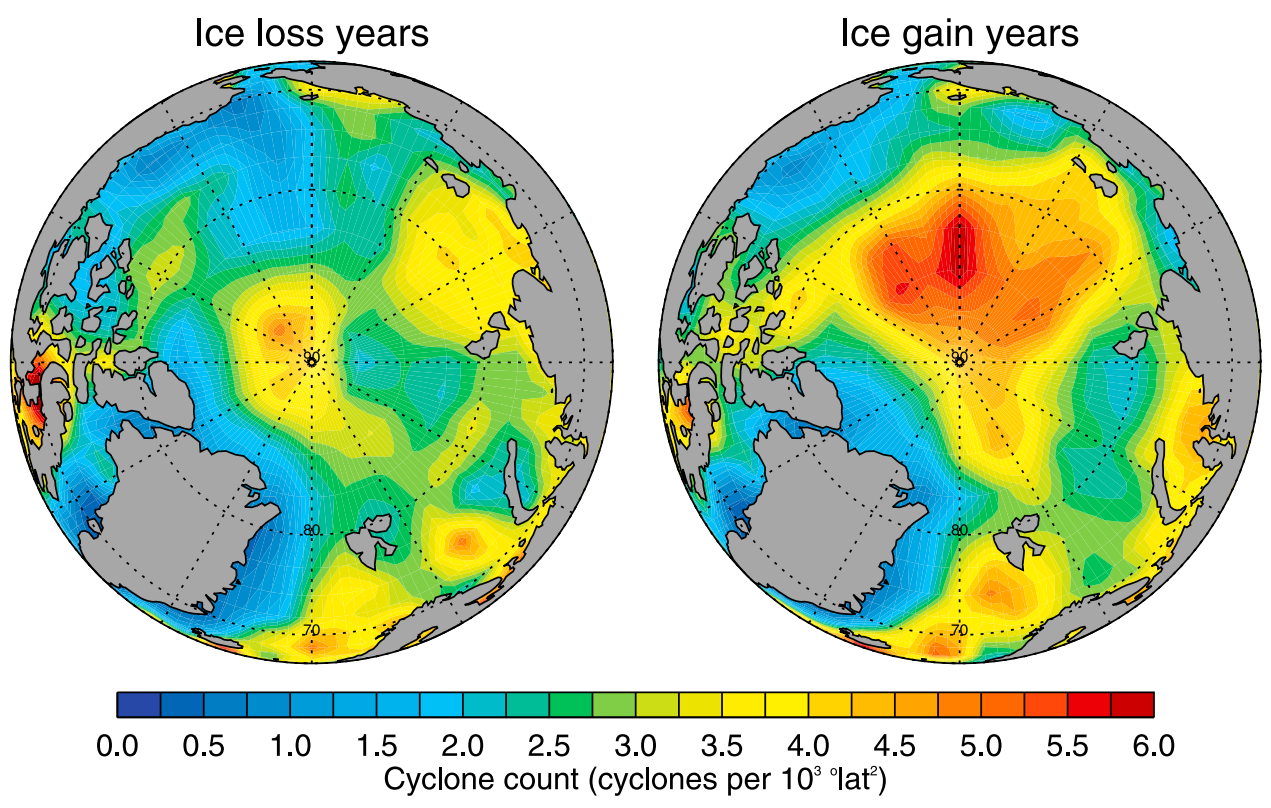

Figure 3. Composite-mean cyclone count (per $10^{3}{ }^{\circ} \mathrm{lat}^{2}$ ) during MJJ of (left) the ILYs and (right) the IGYs.

affect cyclone occurrence. Simmonds and Keay [2009] argue that changes in sea ice cover are more likely to promote modifications in cyclone strength than cyclone frequency. In what follows, we focus on the atmospheric and sea ice conditions during MJJ that precede the anomalously high or low September SIA.

[14] Figure 3 shows maps of the composite-mean cyclone count during MJJ for the IGYs and ILYs. ILYs are associated with far fewer cyclones over the high-latitude Arctic Ocean than IGYs. In particular, the IGYs display a pronounced cyclone maximum over the central Arctic Ocean whereas the ILYs do not. Typically, the central Arctic Ocean is host to a relatively large number of cyclones in summer [Zhang et al., 2004; Serreze and Barrett, 2008; Simmonds et al., 2008] and the climatological mean cyclone spatial distribution resembles the IGY composite map [e.g., Simmonds et al., 2008, Figure 5b]. The lack of a pronounced central Arctic Ocean cyclone maximum in the ILYs suggests that fewer storms formed within or penetrated into the high Arctic in years of large sea ice loss.

[15] Figure 4 shows the tracks for all cyclones that existed in the Arctic during June in the IGYs and ILYs (note here we only show the June tracks for clarity, but similar conclusions to those below can be drawn from the cyclone tracks in May and July; also, recall that the ILY composite contains one year less than the IGY composite). The lack of a pronounced central Arctic Ocean cyclone maximum in ILYs is clearly apparent in the cyclone tracks. Far fewer cyclones pass into the high Arctic during ILYs than IGYs. On average, per year of the composites, 38 cyclones tracks
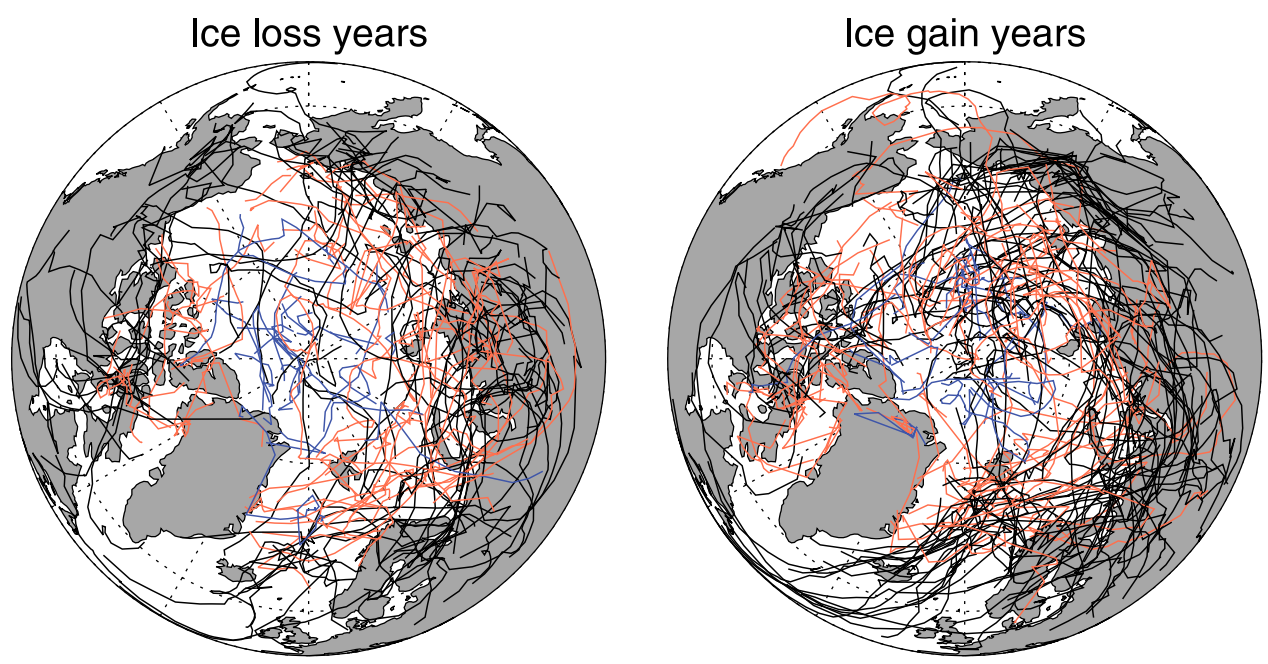

Figure 4. Tracks of all cyclones identified in the Arctic during June of (left) the ILYs and (right) the IGYs. The blue, red, and black colors denote cyclones that formed in the high Arctic $\left(>80^{\circ} \mathrm{N}\right)$, low Arctic $\left(70-80^{\circ} \mathrm{N}\right)$, and midlatitudes $\left(40-70^{\circ} \mathrm{N}\right)$, respectively. 
Table 1. Mean Cyclone Track Count During MJJ of the ILYs, IGYs, and All Years for Three Regions of the Arctic

\begin{tabular}{lccc}
\hline & Ice Loss & Ice Gain & \\
& Years & Years & Climatology \\
\hline High Arctic $\left(>80^{\circ} \mathrm{N}\right)$ & 38.4 & 48.3 & 45 \\
Low Arctic $\left(70-80^{\circ} \mathrm{N}\right)$ & 116.1 & 121.5 & 122.4 \\
Central Arctic Ocean $\left(120^{\circ} \mathrm{E}-120^{\circ} \mathrm{W}\right.$, & 20.4 & 29.1 & 25.2 \\
$\left.\quad 80-90^{\circ} \mathrm{N}\right)$ & & & \\
\hline
\end{tabular}

exist in the high Arctic during MJJ in ILYs compared to 48 in IGYs and a climatological mean of 45 (Table 1). This represents roughly a $20 \%$ decrease in storms during ILYs compared to IGYs and a $15 \%$ decrease from the long-term average. The difference is even more pronounced over the central Arctic Ocean $\left(120^{\circ} \mathrm{E}-120^{\circ} \mathrm{W}, 80-90^{\circ} \mathrm{N}\right)$ where ILYs are associated with a $30 \%$ and $20 \%$ reduction in storms relative to the IGYs and climatology, respectively.

[16] This reduction is illustrated further in Figure 5, which shows the paths of all cyclones that passed over the central Arctic Ocean during MJJ in the IGYs and ILYs. In addition to the fewer cyclones in the central Arctic during ILYs, the most striking difference between the cyclone trajectories in ILYs and IGYs is the almost complete absence of cyclones tracking from the North Atlantic, the Greenland, Norwegian and Barents Seas, and northern Eurasia into the central Arctic during ILYs. During IGYs, a substantial number of cyclones form in these regions, migrate poleward and reach the central Arctic Ocean. Table 2 summarizes the cyclogenesis locations of cyclones reaching the central Arctic during ILYs, IGYs and all years. On average, the number of cyclones forming north of $80^{\circ} \mathrm{N}$ show little difference between the ILYs, IGYs or climatology. This suggests that cyclone formation in the central Arctic is reasonably constant between years, or at least that the September SIA is not sensitive to changes in cyclogenesis in the high Arctic. In contrast, the number of cyclones forming in the low Arctic and midlatitudes are markedly different between ILYs and IGYs, and between ILYs and the climatology. Far fewer storms travel from latitudes south of $80^{\circ} \mathrm{N}$ into the central
Arctic during ILYs. IGYs are associated with slightly above-average numbers of storms moving from the low Arctic and midlatitudes into the central Arctic Basin, but the anomalies are far less pronounced that during ILYs. The average latitude of cyclogenesis during IGYs is $72.4^{\circ} \mathrm{N}$. During ILYs, the mean latitude is almost four degrees further north due to fewer distant storms reaching the central Arctic.

[17] In summary, the cyclone statistics suggest that large year-to-year losses of perennial sea ice are associated with fewer storms over the central Arctic Ocean in MJJ, and that these reductions in storms primarily reflect an absence of cyclones tracking from northern Eurasia and surrounding seas into the central Arctic.

\subsection{Atmospheric Circulation}

[18] In some respects, reduced cyclone frequency favoring low SIA seems counterintuitive, as storms transport heat into the Arctic and help break up the ice cover making it more susceptible to melt. To gain insight into the physical associations, we now consider the mean MJJ atmospheric circulation associated with ILYs and IGYs. Figure 6 shows the composite-mean MSLP and surface wind stress patterns. In the ILYs, a high pressure center is located in the Beaufort Sea and pressures above $1014 \mathrm{hPa}$ are found over most of the Arctic Ocean. The wind is predominantly anticyclonic with a local closed circulation in the Beaufort Sea and a larger jetlike circulation from the Chukchi Sea toward the Barents Sea. By contrast in the IGYs, the Beaufort Sea high pressure center is much weaker and smaller, and there is low pressure centered over the central Arctic Ocean but extending to much of the basin. The wind is predominantly cyclonic around a midpoint in the central Arctic Ocean. Both patterns reflect departures from the climatological MJJ mean, as revealed in Figure 7 that shows the compositemean MSLP anomalies and wind stresses anomalies relative to the long-term average. ILYs are associated with elevated MSLP and strengthened anticyclonic circulation over much of the Arctic Ocean whereas IGYs are linked to reduced
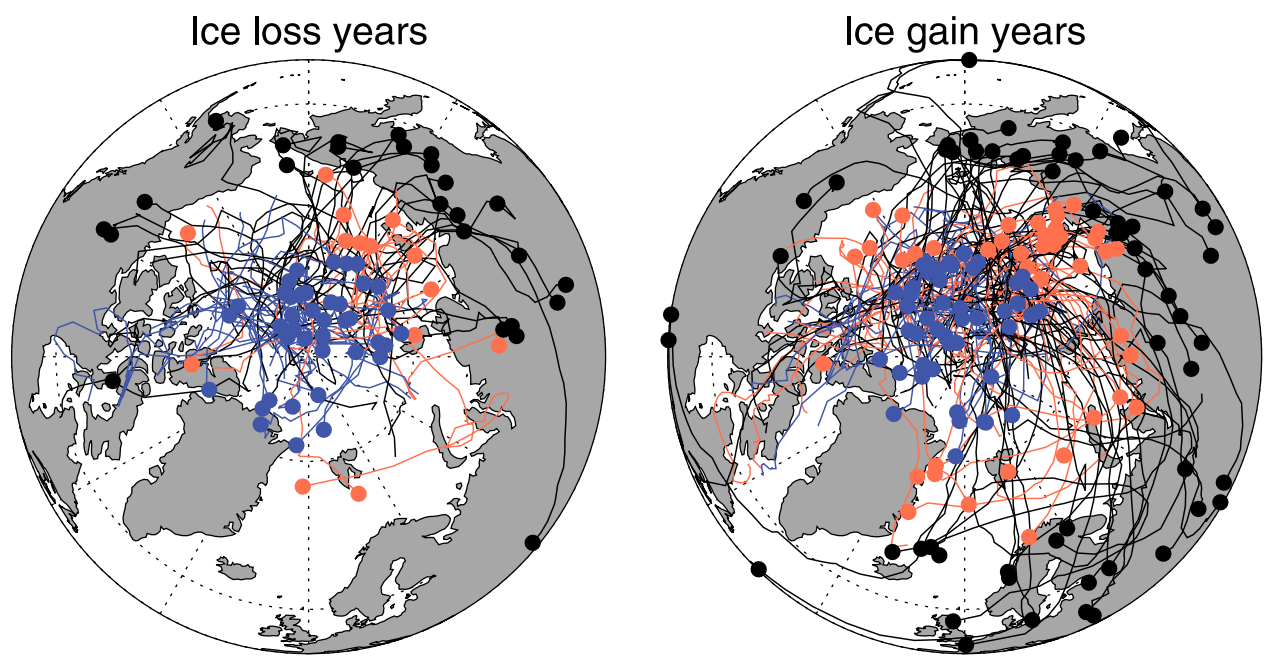

Figure 5. Tracks of all cyclones identified over the central Arctic Ocean $\left(120^{\circ} \mathrm{E}-120^{\circ} \mathrm{W}, 80-90^{\circ} \mathrm{N}\right)$ during MJJ of (left) the ILYs and (right) the IGYs. The dots show the locations of cyclone formation, and the colors are the same as Figure 4. 
Table 2. Formation Locations of Cyclones That Entered the Central Arctic Ocean $\left(120^{\circ} \mathrm{E}-120^{\circ} \mathrm{W} ; 80-90^{\circ} \mathrm{N}\right)^{\mathrm{a}}$

\begin{tabular}{lccc}
\hline & $\begin{array}{c}\text { Ice Loss } \\
\text { Years }\end{array}$ & $\begin{array}{c}\text { Ice Gain } \\
\text { Years }\end{array}$ & Climatology \\
\hline High Arctic $\left(>80^{\circ} \mathrm{N}\right)$ & 10.2 & 9.3 & 8.1 \\
Low Arctic $\left(70-80^{\circ} \mathrm{N}\right)$ & 3.6 & 8.1 & 7.2 \\
Midlatitudes $\left(40-70^{\circ} \mathrm{N}\right)$ & 6.6 & 11.7 & 9.9 \\
Mean latitude & $76.3^{\circ} \mathrm{N}$ & $72.4^{\circ} \mathrm{N}$ & $72.4^{\circ} \mathrm{N}$ \\
\hline
\end{tabular}

${ }^{a}$ Locations are represented by the mean number of cyclones forming per MJJ in three latitude bands during ILYs, IGYs, and all years. Also shown are the mean latitudes of cyclogenesis during ILYs, IGYs, and all years.

MSLP and cyclonic circulation anomalies, particularly over the central Arctic Ocean.

[19] These MSLP and wind anomalies are closely related to the changes in cyclone activity. Fewer storms during ILYs contribute to the above-average MSLP whereas more storms during IGYs contribute to below-average MSLP. The correlation between MJJ Arctic-mean MSLP and cyclone count across all years is -0.80 (not shown).

\subsection{Sea Ice Drift}

[20] Previous studies have shown that sea ice motion is strongly influenced by storm activity in the Arctic Basin, particularly in the Beaufort Sea region [Zhang et al., 2004; Lukovich and Barber, 2006; Asplin et al., 2009]. Typically, high pressure dominates over the Arctic Ocean and the sea ice drifts clockwise (anticyclonic) around a center in the Beaufort Sea. A predominantly anticyclonic ice gyre tends to transport thick ice away from the Beaufort Sea toward to Chukchi Sea, where it is more prone to melt, and increase the transpolar drift of ice from the Chukchi Sea region toward Fram Strait, where it is exported from the Arctic Basin and melts [e.g., Lukovich and Barber, 2006]. An increase in storms reaching the central Arctic in summer can weaken the anticyclonic ice circulation, which tends to reduce ice melt and export [Lukovich and Barber, 2006; Asplin et al., 2009]. Conversely, fewer summer storms may strengthen the ice gyre and the transpolar drift stream (TDS); both of which favor sea ice melt and export.

[21] Figure 8 shows the composite-mean sea ice motion during the ILYs and IGYs (note that here, 2007 is missing from the ILY composite and 2009 is missing from the IGY composite because data for these years were unavailable). The anticyclonic Beaufort Sea ice gyre can be seen in both composites, but is slightly larger during ILYs. The differences between the TDS are more striking. During ILYs there is a strong and wide TDS, with particularity large ice velocities from the central Arctic Ocean toward Fram Strait. In comparison, the TDS is weaker, narrower and shifted toward the western hemisphere during IGYs. The TDS is almost nonexistent in the eastern hemisphere during IGYs. Figure 9 shows how these composite patterns differ from the long-term mean. A salient feature of the ice motion anomalies during ILYs is an intensification of the TDS and of the flow of ice from the Beaufort Sea into the Chukchi Sea. The predominant feature during IGYs are cyclonic ice motion anomalies in the central Arctic that are associated with the additional storms and cyclonic wind anomalies. The cyclonic ice motion anomalies result in an intensification of the TDS on its western flank and a weakening, or shutoff, of the TDS on its eastern side. The net effect is a weaker, narrower and shifted TDS in IGYs (Figure 8). Interestingly, the ice velocities through Fram Strait are comparable in IGYs and ILYs, and both are greater than the long-term average. This suggests that processes internal to the Arctic Basin play a larger role than Fram Strait ice export in driving the large changes in September SIA.

\subsection{Cloud Cover}

[22] Changes in ice motion are not the only factor related to cyclone activity that may influence the SIA. Figure 10 shows the MJJ composite-mean total cloud cover anoma-

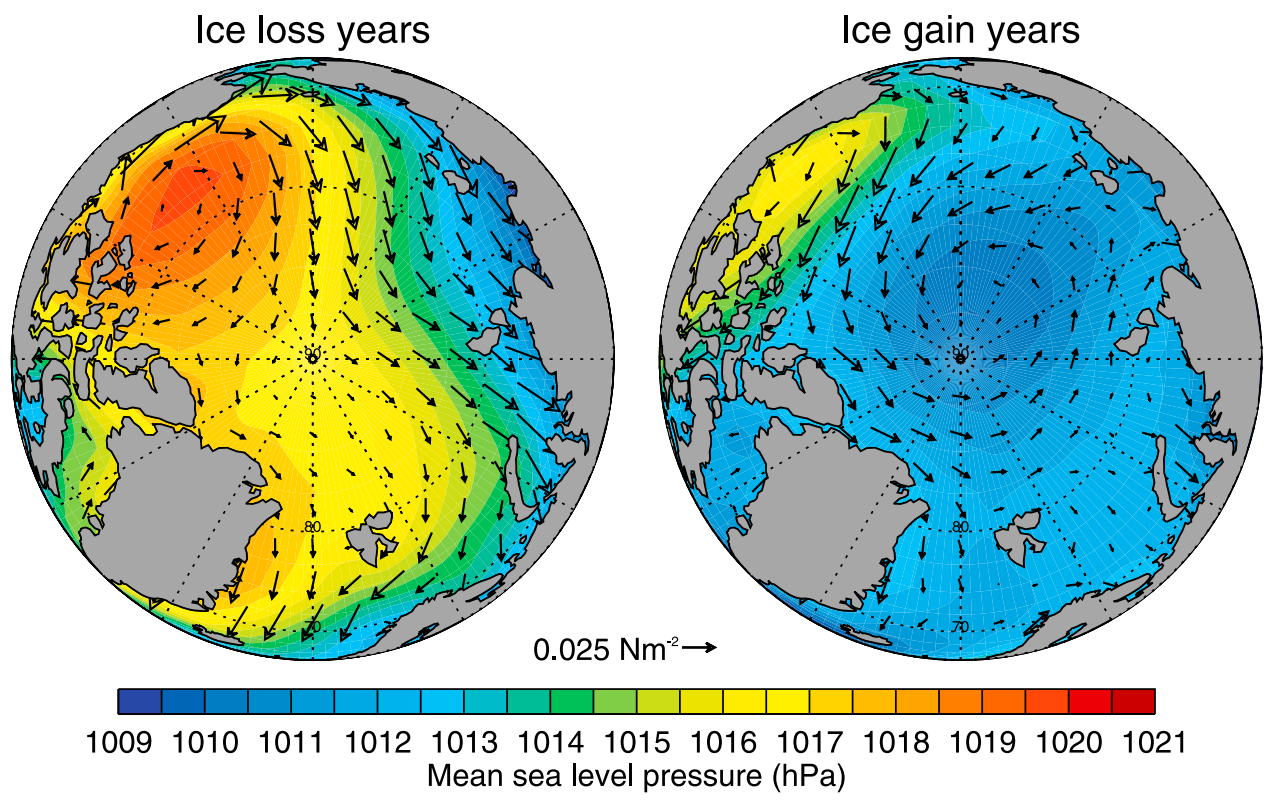

Figure 6. Composite-mean surface wind stress vectors (arrows) and MSLP (shading) during MJJ of (left) the ILYs and (right) the IGYs. 


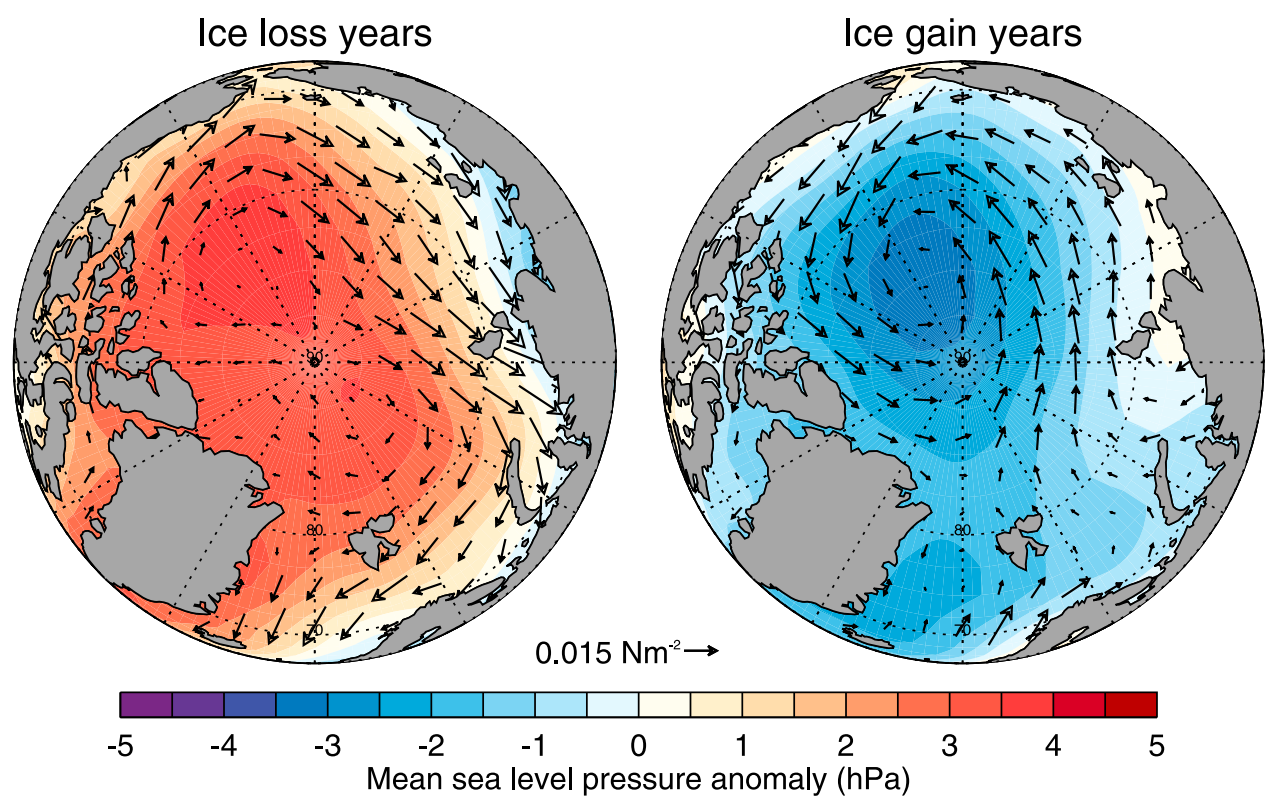

Figure 7. Composite-mean surface wind stress anomaly vectors (arrows) and MSLP anomalies (shading) during MJJ of (left) the ILYs and (right) the IGYs.

lies based on satellite data (here, data availability dictates that 2009 is not included in the IGY composite but 2007 is included in the ILY composite). ILYs that are associated with reduced cyclone activity are also, unsurprisingly, associated with reduced cloud cover. Negative cloud cover anomalies are found over most of the Arctic Ocean. During IGYs, there are positive cloud cover anomalies over the central and western Arctic Ocean, associated with more cyclones in these regions (Figure 4), but negative cloud cover anomalies over the Barents, Kara and Laptev Seas. The cause of these latter negative anomalies is unclear.
[23] Changes in cloud cover have competing effects on the surface energy balance. On one hand, decreases in cloud cover increase the incoming solar radiation and may enhance surface ice melt. On the other hand, decreased cloud cover can have a cooling influence at the surface by reducing the amount of downward longwave radiation. The net effect of these competing influences varies through the year, with latitude, and according to the surface albedo [Intrieri et al., 2002; Screen and Simmonds, 2010a]. To estimate the mean cloud radiative forcing in MJJ, we have compared the net surface radiation under clear-sky and allsky conditions (Figure 11). All radiation fields used are

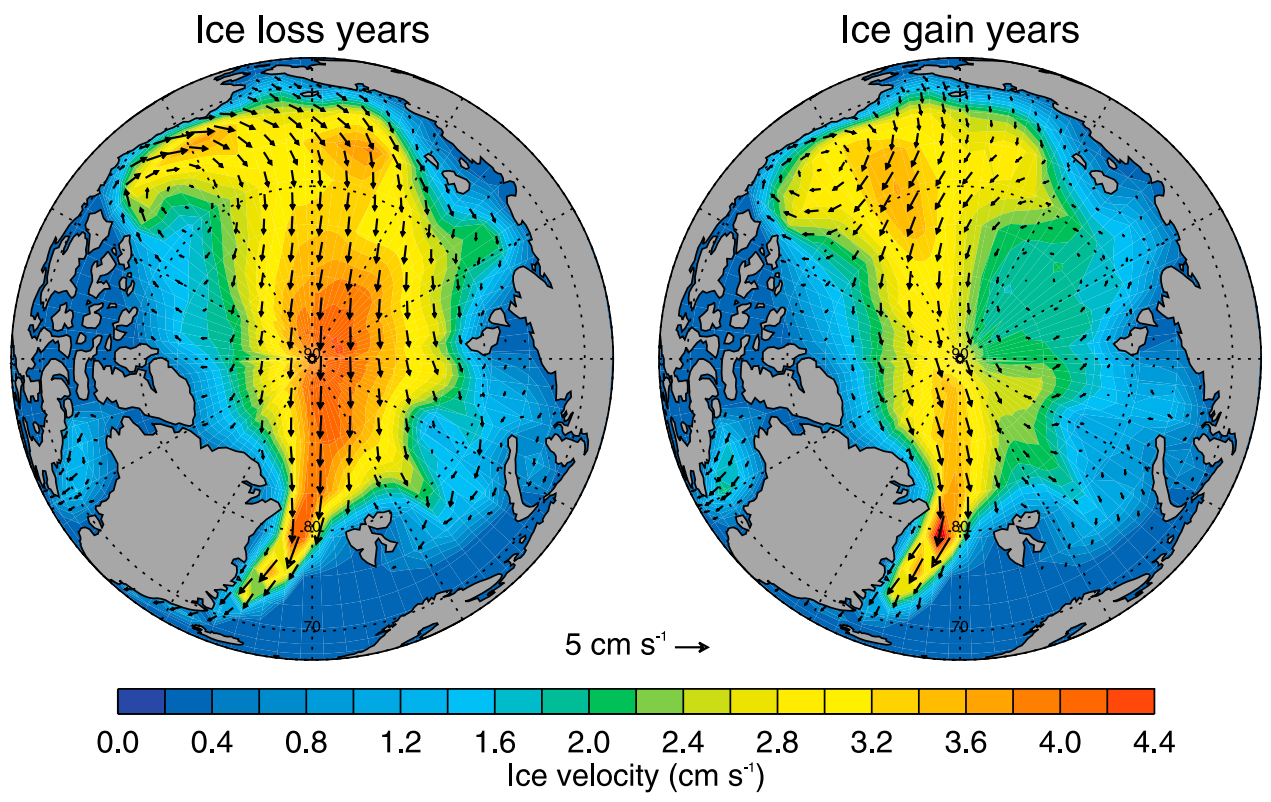

Figure 8. Composite-mean ice motion vectors (arrows) and ice velocity (shading) during MJJ of (left) the ILYs and (right) the IGYs. 


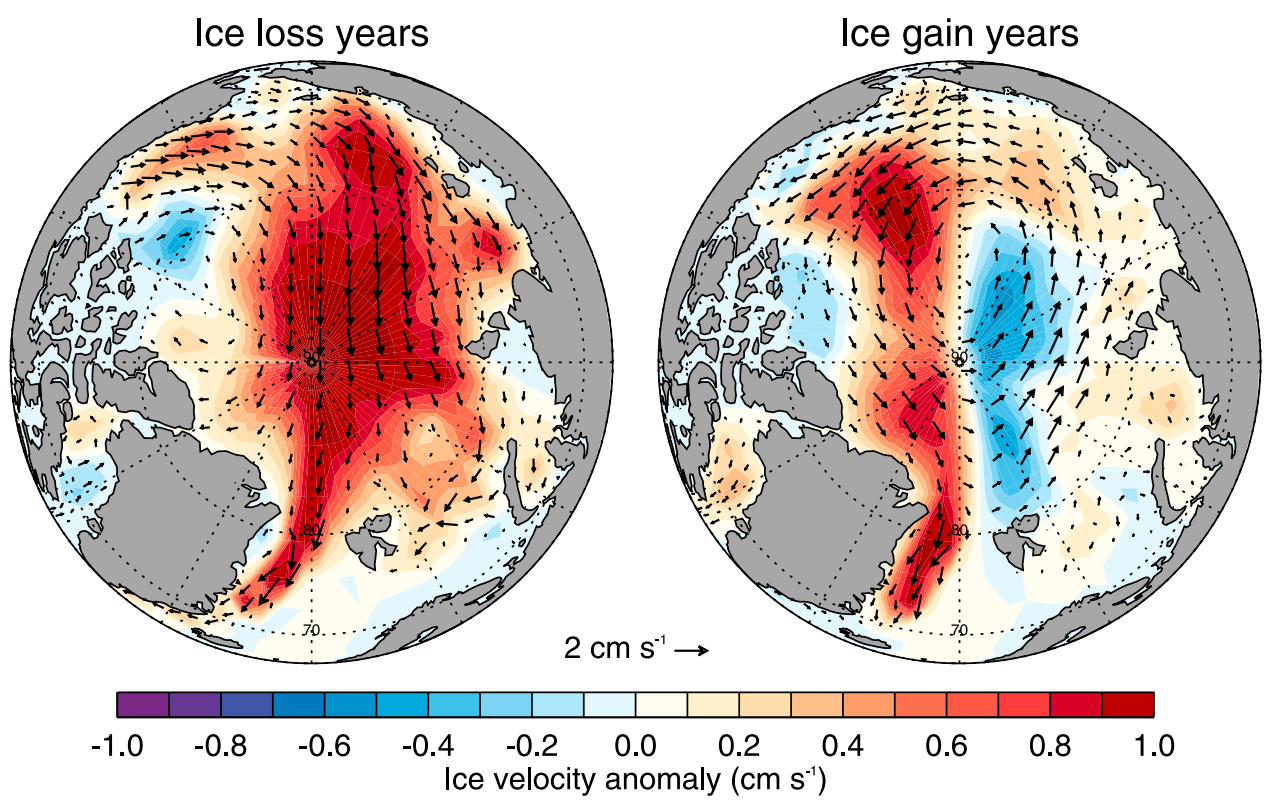

Figure 9. Composite-mean ice motion anomaly vectors (arrows) and ice velocity anomalies (shading) during MJJ of (left) the ILYs and (right) the IGYs.

climatological means from ERA-Interim, 1989-2008, consistent with Screen and Simmonds [2010a]. Figure 11 suggests that over most of the Arctic Basin during MJJ, the warming and cooling effects of clouds approximately cancel each other out, resulting in near-zero cloud radiative forcing. Although Figure 11 masks temporal variability, both within the MJJ season (from May to July there is a transition from a net warming to net cooling effect) and between years, it suggests that the MJJ-mean cloud cover anomalies shown in Figure 10 may have only a weak influence on the sea ice. In the Norwegian, Greenland and Barents Seas, the cloud shading effect dominates over the greenhouse effect, and the presence of cloud has a comparatively strong cooling influence (Figure 11). However, the cloud cover anomalies in these regions are modest in both the IGYs and ILYs (Figure 10).

[24] Although the direct radiative impacts of the cloud cover anomalies may be small in the Arctic during late spring and early summer (Figure 11) [Schweiger et al., 2008], other closely related changes may be important. For example, reduced cloud cover may be associated with decreases in snowfall and snow cover, which lowers the

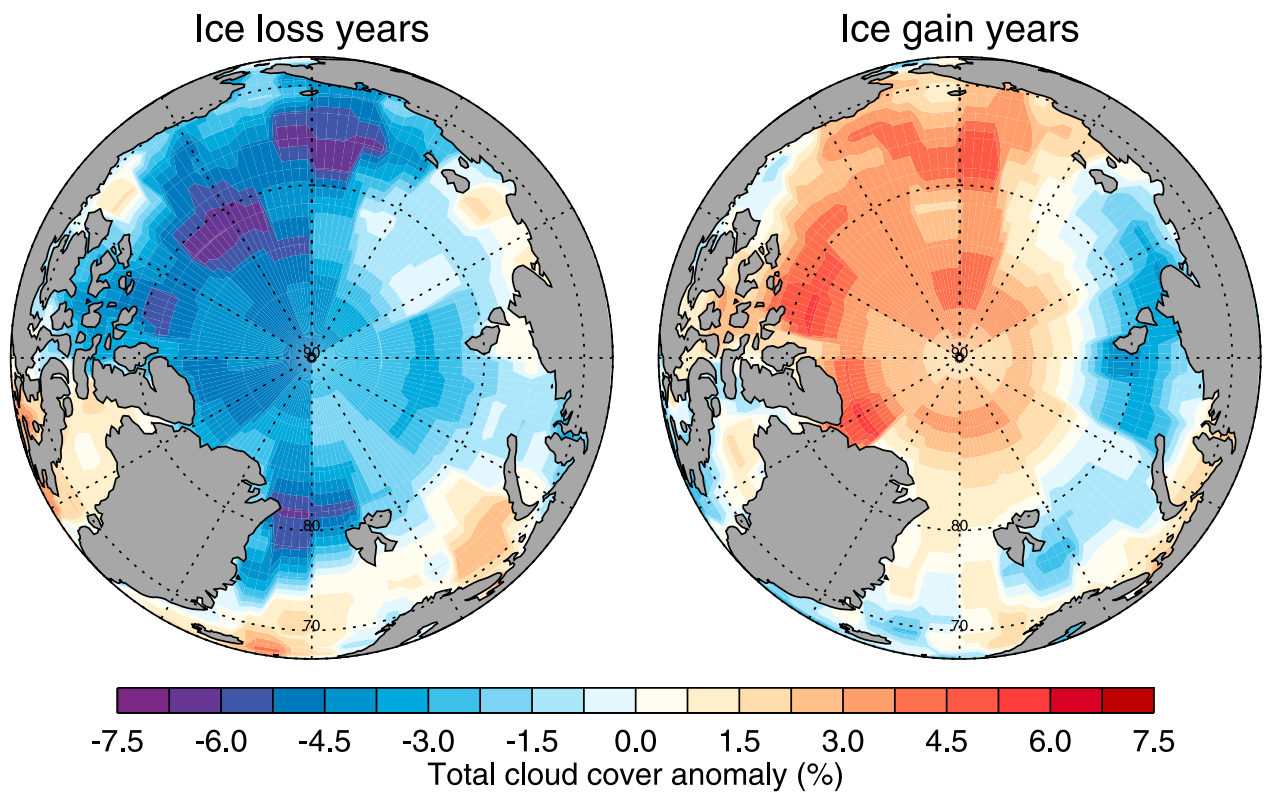

Figure 10. Composite-mean total cloud cover anomalies during MJJ of (left) the ILYs and (right) the IGYs. 


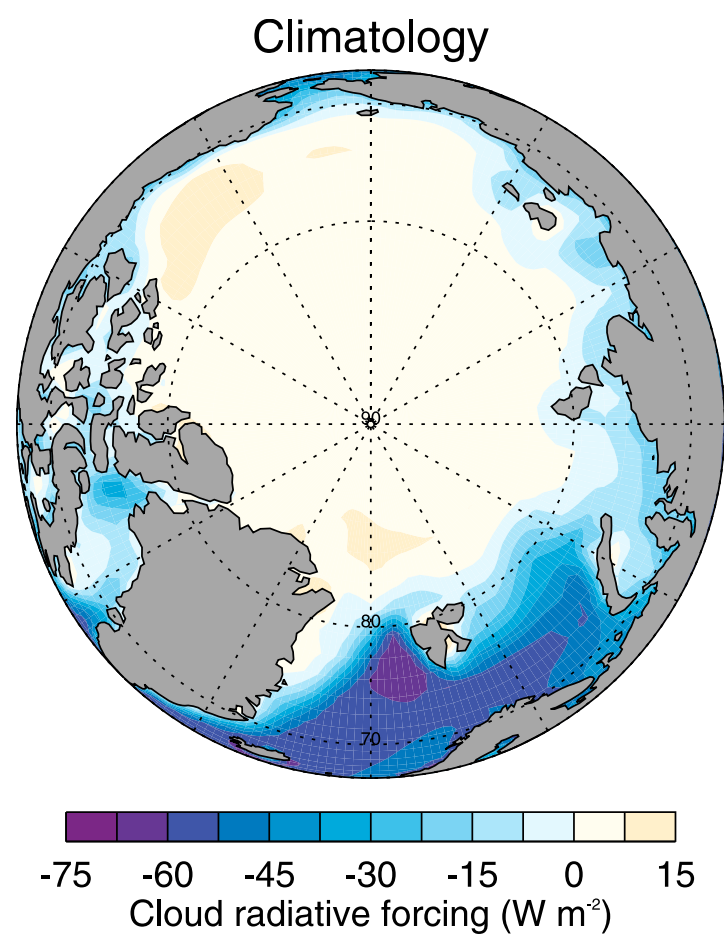

Figure 11. Climatological mean (1989-2008) differences between the net surface radiation under all-sky and clearsky conditions from ERA-Interim. Blue (red) shading indicates that the presence of cloud has a net cooling (warming) effect of the surface.

surface albedo and enhances surface ice melt [Screen and Simmonds, 2011b].

\section{Discussion and Conclusions}

[25] The results show that interannual variations in perennial (September) sea ice are related to anomalous Arctic cyclone activity during the preceding late spring and early summer. In particular, fewer cyclones in the central Arctic Ocean during MJJ appear to favor low SIA at the end of the melt season. Years with large losses of perennial ice are characterized by abnormal cyclone distributions and tracks during MJJ. They lack the normal maximum in cyclone activity over the central Arctic Ocean and cyclones that track from Eurasia into the central Arctic are largely absent. Serreze and Barrett [2008] noted the importance of storms generated over the Eurasian continent in sustaining the summer cyclone maximum over the Arctic Ocean. Our results support this conclusion and further show that a reduction of the influx of these cyclones fosters anomalously low September sea ice. Our results also suggest that a strengthening of the central Arctic cyclone maximum during MJJ helps preserve the ice cover and leads to anomalously high September sea ice. However, the relationship does not appear to be entirely linear with a clearer association between low cyclone activity and reduced sea ice than between high cyclone activity and increased sea ice.

[26] We have revealed close and consistent links between changes in cyclone activity, atmospheric circulation, ice motion and cloud cover. All of these changes likely have an effect on ice melt rates and, therefore, on the amount of sea ice that survives the melt season. It is beyond the scope of this study to separate the relative contributions of these interconnected influences on the September SIA. However, it is important to note that (strong) statistical associations between sea ice and any particular atmospheric parameter (e.g., cloud cover, wind) may not necessarily imply a physical connection. For instance, Eastman and Warren [2010] show statistical associations between low September sea ice extent and decreased middle and precipitating clouds in the preceding summer. However, the direct physical connection could be between ice cover and cyclone activity. The radiative impacts of cloud cover changes may be weak and the statistical association may be explained by other covarying factors that are related to changes in cyclone activity. Equally, the strong correlations between the wind field and sea ice extent shown by other authors [Ogi and Wallace, 2007; Ogi et al., 2010] may not arise solely due to changes in wind but also other implicit changes influenced by cyclone activity.

[27] Our focus has been on large interannual changes in sea ice, but in light of the pronounced downward trend in sea ice over the last three decades, it is worthwhile briefly considering the potential role of cyclone changes in longerterm sea ice variability. We found no significant trends in late spring or summer Arctic cyclone frequency over the period 1979-2009, and neither did Simmonds et al. [2008] over a similar period but with different data sets. Serreze and Barrett [2008] also found no significant trend in summer cyclone occurrence over the central Arctic during the longer period 1958-2005. Therefore, it seems unlikely that multidecadal changes in cyclone activity are a primary cause of the observed decline in perennial sea ice. However, this does not imply that future changes in Arctic storm activity will be peripheral to determining when, if as projected, a seasonally ice-free Arctic Ocean is realized. There is mounting evidence that suggests that the sea ice cover is becoming increasing responsive and susceptible to episodic forcing [Maslanik et al., 2007; Lindsay et al., 2009]. As the summer ice cover has declined, exposing more open water to wind forcing, the ice pack has become more mobile [Hakkinen et al., 2008]. Moreover, the thinner ice pack means less energy is required to achieve a reduction in areal coverage. Given this, it is likely that changes in cyclone activity will continue to play an important role in sea ice variability over the coming decades.

[28] Acknowledgments. We thank the Japan Meteorological Agency, United Kingdom Meteorological Office, National Snow and Ice Data Center, and National Aeronautics and Space Administration for providing data. Parts of this research were supported by funding from the Australian Research Council. Clara Deser and two anonymous reviewers are thanked for their insightful comments.

\section{References}

Asplin, M. G., J. V. Lukovich, and D. G. Barber (2009), Atmospheric forcing of the Beaufort Sea ice gyre: Surface pressure climatology and sea ice motion, J. Geophys. Res., 114, C00A06, doi:10.1029/2008JC005127.

Boé, J., A. Hall, and X. Qu (2009), September sea-ice cover in the Arctic Ocean projected to vanish by 2100 , Nat. Geosci., 2, 341-343, doi:10.1038/ngeo467. 
Brümmer, B., G. Müller, and H. Hoeber (2003), A Fram Strait cyclone: Properties and impact on ice drift as measured by aircraft and buoys, J. Geophys. Res., 108(D7), 4217, doi:10.1029/2002JD002638.

Brümmer, B., D. Schröder, G. Müller, G. Spreen, A. Jahnke-Bornemann, and J. Launiainen (2008), Impact of a Fram Strait cyclone on ice edge, drift, divergence, and concentration: Possibilities and limits of an observational analysis, J. Geophys. Res., 113, C12003, doi:10.1029/2007JC004149.

Comiso, J. C., C. L. Parkinson, R. Gersten, and L. Stock (2008), Accelerated decline in the Arctic sea ice cover, Geophys. Res. Lett., 35, L01703, doi:10.1029/2007GL031972.

Deser, C., and H. Teng (2008), Evolution of Arctic sea ice concentration trends and the role of atmospheric forcing, 1979-2007, Geophys. Res. Lett., 35, L02504, doi:10.1029/2007GL032023.

Eastman, R., and S. G. Warren (2010), Interannual variations of Arctic cloud types in relation to sea ice, J. Clim., 23, 4216-4232, doi:10.1175/ 2010JCLI3492.1.

Fowler, C. (2003) Polar Pathfinder daily $25 \mathrm{~km}$ EASE-grid sea ice motion vectors, http://nsidc.org/data/nsidc-0116.html, Natl. Snow and Ice Data Cent., Boulder, Colo. [Updated in 2008.]

Francis, J. A., and E. Hunter (2007), Changes in the fabric of the Arctic's greenhouse blanket, Environ. Res. Lett., 2, 045011, doi:10.1088/17489326/2/4/045011

Graversen, R. G., T. Mauritsen, S. Drijfhout, M. Tjernström, and S. Mårtensson (2010), Warm winds from the Pacific caused extensive Arctic sea-ice melt in summer 2007, Clim. Dyn., 36, 2103-2112, doi:10.1007/s00382-010-0809-z.

Hakkinen, S., A. Proshutinsky, and I. Ashik (2008), Sea ice drift in the Arctic since the 1950s, Geophys. Res. Lett., 35, L19704, doi:10.1029/ 2008GL034791.

Intrieri, J. M., C. W. Fairall, M. D. Shupe, P. O. G. Persson, E. L. Andreas, P. S. Guest, and R. E. Moritz (2002), An annual cycle of Arctic surface cloud forcing at SHEBA, J. Geophys. Res., 107(C10), 8039, doi:10.1029/ 2000JC000439

Kay, J. E., T. L'Ecuyer, A. Gettelman, G. Stephens, and C. O’Dell (2008), The contribution of cloud and radiation anomalies to the 2007 Arctic sea ice extent minimum, Geophys. Res. Lett., 35, L08503, doi:10.1029/ 2008GL033451.

Lindsay, R. W., J. Zhang, A. Schweiger, M. Steele, and H. Stern (2009), Arctic sea ice retreat in 2007 follows thinning trend, J. Clim., 22, 165-176, doi:10.1175/2008JCLI2521.1.

Lukovich, J. V., and D. G. Barber (2006), Atmospheric controls on sea ice motion in the southern Beaufort Sea, J. Geophys. Res., 111, D18103, doi: 10.1029/2005JD006408.

Maslanik, J. A., C. Fowler, J. Stroeve, S. Drobot, J. Zwally, D. Yi, and W. Emery (2007), A younger, thinner Arctic ice cover: Increased potential for rapid, extensive sea-ice loss, Geophys. Res. Lett., 34, L24501, doi:10.1029/2007GL032043.

McCabe, G. J., M. P. Clark, and M. C. Serreze (2001), Trends in Northern Hemisphere surface cyclone frequency and intensity, J. Clim., 14, 2763-2768, doi:10.1175/1520-0442(2001)014<2763:TINHSC $>2.0 . C O ; 2$.

Murray, R. J., and I. Simmonds (1995), Responses of climate and cyclones to reductions in Arctic winter sea ice, J. Geophys. Res., 100(C3), 4791-4806, doi:10.1029/94JC02206.

Ogi, M., and J. M. Wallace (2007), Summer minimum Arctic sea ice exten and the associated summer atmospheric circulation, Geophys. Res. Lett. 34, L12705, doi:10.1029/2007GL029897.

Ogi, M., K. Yamazaki, and J. M. Wallace (2010), Influence of winter and summer surface wind anomalies on summer Arctic sea ice extent, Geophys. Res. Lett., 37, L07701, doi:10.1029/2009GL042356.

Onogi, K., et al. (2007), The JRA-25 reanalysis, J. Meteorol. Soc. Jpn., 85 , 369-432, doi:10.2151/jmsj.85.369.

Perovich, D. K., J. A. Richter-Menge, K. F. Jones, and B. Light (2008), Sunlight, water, and ice: Extreme Arctic sea ice melt during the summer of 2007, Geophys. Res. Lett., 35, L11501, doi:10.1029/2008GL034007.

Pinto, J. G., T. Spangehl, U. Ulbrich, and P. Speth (2005), Sensitivities of a cyclone detection and tracking algorithm: Individual tracks and climatology, Meteorol. Z., 14, 823-838, doi:10.1127/0941-2948/2005/0068.

Rayner, N. A., D. E. Parker, E. B. Horton, C. K. Folland, L. V. Alexander D. P. Rowell, E. C. Kent, and A. Kaplan (2003), Global analyses of sea surface temperature, sea ice, and night marine air temperature since the late nineteenth century, J. Geophys. Res., 108(D14), 4407, doi:10.1029/ 2002JD002670.

Raible, C. C., P. M. Della-Marta, C. Schwierz, H. Wernli, and R. Blender (2008), Northern Hemisphere extratropical cyclones: A comparison of detection and tracking methods and different reanalyses, Mon. Weather Rev., 136, 880-897, doi:10.1175/2007MWR2143.1.

Rossow, W., and R. Schiffer (1999), Advances in understanding clouds from ISCCP, Bull. Am. Meteorol. Soc., 80, 2261-2287, doi:10.1175/ 1520-0477(1999)080<2261:AIUCFI $>2.0 . C O ; 2$.

Schweiger, A. J., J. Zhang, R. W. Lindsay, and M. Steele (2008), Did unusually sunny skies help drive the record sea ice minimum of 2007?, Geophys. Res. Lett., 35, L10503, doi:10.1029/2008GL033463.

Screen, J. A., and I. Simmonds (2010a), The central role of diminishing sea ice in recent Arctic temperature amplification, Nature, 464, 1334-1337, doi:10.1038/nature09051.

Screen, J. A., and I. Simmonds (2010b), Increasing fall-winter energy loss from the Arctic Ocean and its role in Arctic temperature amplification, Geophys. Res. Lett., 37, L16707, doi:10.1029/2010GL044136.

Screen, J. A., and I. Simmonds (2011a), Erroneous Arctic temperature trends in the ERA-40 reanalysis: A closer look, J. Clim., 24, 2620-2627, doi:10.1175/2010JCLI4054.1.

Screen, J. A., and I. Simmonds (2011b), Declining summer snowfall in the Arctic: Causes, impacts and feedbacks, Clim. Dyn., doi:10.1007/s00382$011-1105-2$, in press.

Sepp, M., and J. Jaagus (2011), Changes in the activity and tracks of Arctic cyclones, Clim. Change, 105, 577-595, doi:10.1007/s10584-010-9893-7.

Serreze, M. C., and A. P. Barrett (2008), The summer cyclone maximum over the central Arctic Ocean, J. Clim., 21, 1048-1065, doi:10.1175/ 2007JCLI1810.1.

Serreze, M. C., M. M. Holland, and J. Stroeve (2007), Perspectives on the Arctic's shrinking sea-ice cover, Science, 315, 1533-1536, doi:10.1126/ science. 1139426

Serreze, M. C., A. P. Barrett, J. C. Stroeve, D. N. Kindig, and M. M. Holland (2009), The emergence of surface-based Arctic amplification, Cryosphere, 3, 11-19, doi:10.5194/tc-3-11-2009.

Simmonds, I., and K. Keay (2009), Extraordinary September sea ice reductions and their relationships with storm behavior over 1979-2008, Geophys. Res. Lett., 36, L19715, doi:10.1029/2009GL039810.

Simmonds, I., C. Burke, and K. Keay (2008), Arctic climate change as manifest in cyclone behavior, J. Clim., 21, 5777-5796, doi:10.1175/ 2008JCLI2366.1.

Sorteberg, A., and B. Kvingedal (2006), Atmospheric forcing on the Barents Sea winter sea ice extent, J. Clim., 19, 4772-4784, doi:10.1175/ JCLI3885.1.

Sorteberg, A., and J. E. Walsh (2008), Seasonal cyclone variability at $70^{\circ} \mathrm{N}$ and its impact on moisture transport into the Arctic, Tellus, Ser. A, 60 570-586, doi:10.1111/j.1600-0870.2008.00314.x.

Stroeve, J., M. M. Holland, W. Meier, T. Scambos, and M. C. Serreze (2007), Arctic sea ice decline: Faster than forecast, Geophys. Res. Lett., 34, L09501, doi:10.1029/2007GL029703.

Tsukernik, M., C. Deser, M. Alexander, and R. Tomas (2010), Atmospheric forcing of Fram Strait sea ice export: A closer look, Clim. Dyn., 35, 1349-1360, doi:10.1007/s00382-009-0647-z.

Wang, M., and J. E. Overland (2009), A sea ice free summer Arctic within 30 years?, Geophys. Res. Lett., 36, L07502, doi:10.1029/2009GL037820.

Wang, J., J. Zhang, E. Watanabe, M. Ikeda, K. Mizobata, J. E. Walsh, X. Bai, and B. Wu (2009), Is the Dipole Anomaly a major driver to record lows in Arctic summer sea ice extent?, Geophys. Res. Lett., 36 , L05706, doi:10.1029/2008GL036706.

Woodgate, R. A., T. Weingartner, and R. Lindsay (2010), The 2007 Bering Strait oceanic heat flux and anomalous Arctic sea-ice retreat, Geophys. Res. Lett., 37, L01602, doi:10.1029/2009GL041621.

Zhang, X., J. E. Walsh, J. Zhang, U. S. Bhatt, and M. Ikeda (2004), Climatology and interannual variability of Arctic cyclone activity: 1948-2002, J. Clim., 17, 2300-2317, doi:10.1175/1520-0442(2004)017< 2300: $\mathrm{CAIVOA}>2.0 . \mathrm{CO} ; 2$

K. Keay, J. A. Screen, and I. Simmonds, School of Earth Sciences, University of Melbourne, Melbourne, Vic 3010, Australia. (screenj@ unimelb.edu.au) 